\title{
ENTRE O ENSINO E A EXTENSÃO: A FORMAÇÃO PARA A EDUCAÇÃO INCLUSIVA DO LICENCIADO EM QUÍMICA - UM RELATO DE EXPERIÊNCIA
}

\section{BETWEEN TEACHING AND EXTENSION: CHEMISTRY TEACHERS' TRAINING FOR INCLUSIVE EDUCATION - AN EXPERIENCE REPORT}

\author{
Alice Cristina Souza Lacerda Melo de Souza* \\ Cleuza Diogo Antunes** \\ Carmen Tereza Velanga*** \\ Marlene Rodrigues*
}

\section{RESUMO:}

A formação inicial de professores destinada ao atendimento das demandas da Educação Especial, na perspectiva inclusiva, constitui-se num desafio para as Instituiçốes formadoras. Este relato resulta das discussões didático-pedagógicas ocorridas na disciplina de Educação Inclusiva, do Curso de Licenciatura em Química do IFROCampus Ji Paraná-RO, que culminaram com o desenvolvimento de um projeto de extensão, que consistiu na integração dos conhecimentos teóricos vivenciados em sala de aula e na promoção de ações e intervenções pedagógicas junto a grupos externos à Instituição. As intervenções foram organizadas em oficinas, com producão de materiais didáticos, e ocorreram em 2017, em Ji-Paraná-RO. A partir dos resultados coletados, infere-se que discutir a educação inclusiva por meio de projetos de extensão aliados ao ensino contribui para uma aprendizagem significativa, promovendo a aceitacão da temática entre os acadêmicos e capacitando-os quanto ao compromisso ético e político na promoção de práticas pedagógicas inclusivas no ensino da Química.

Palavras-chave: Licenciatura em Química; Formação de professores; Educação especial; Educação inclusiva; Extensão.

\begin{abstract}
:
The initial training of teachers to comply with the demands of Special Education in the Inclusive perspective is a challenge for the training institutions. This report is the result of the didactic-pedagogical discussions that took place in the subject Inclusive Education in the Teaching Chemistry Undergraduate Course at IFRO - Campus Ji-Paraná-RO, which resulted in the development of an extension project that consisted in the integration of the theoretical knowledge lived in the classroom and in the promotion of pedagogical actions and interventions with groups outside the Institution. The interventions were organized in workshops with production of teaching materials and took place in 2017 in Ji-Paraná-RO. Based on the results, it is inferred that discussing inclusive education through extension projects allied to teaching contributes to meaningful learning by promoting the acceptance of the theme among academics and empowering them with regard to ethical and political commitment in the promotion of inclusive pedagogical practices in the teaching of Chemistry.
\end{abstract}

Keywords: Teaching Chemistry Undergraduate Course; Teacher training; Special education; Inclusive education; Extension. 


\section{Introdução}

$\mathrm{O}$ ingresso de estudantes público-alvo da educação especial no ensino regular brasileiro é garantido pela Constituição Brasileira (BRASIL,1988), em seu Artigo 205, e por outros documentos norteadores que discutem a inclusão no cenário nacional, assegurando que as pessoas com deficiência não sejam alvo de discriminação. Entre os documentos normativos e legais destacam-se o Estatuto da Criança e do Adolescente (BRASIL, 1990), a Lei de Diretrizes e Bases da Educação Nacional 9394/1996 (BRASIL,1996), a Política Nacional da Educação Especial na Perspectiva da Educação Inclusiva (BRASIL, 2008), a Lei Brasileira de Inclusão $\mathrm{n}^{\circ}$ 13.146 (BRASIL, 2015), bem como o Plano Nacional de Educação (2014-2024), dentre outros decretos e pareceres específicos.

Sabe-se que embora garantido o ingresso dos Estudantes Público Alvo da Educação Especial (EPAEE) à escola regular, nem sempre a permanência e o sucesso escolar caminham juntos. Essa equação ainda não resolvida é um entrave a ser removido diariamente, uma vez que grandes conquistas não acontecem instantaneamente nem são resultados de fórmulas mágicas, exigindo políticas públicas eficazes e, por certo,

[...] a igualdade de oportunidades é perversa quando garante o acesso, por exemplo, à escola comum, de pessoas com alguma deficiência de nascimento ou de pessoas que não têm a mesma possibilidade das demais de passar pelo processo educacional em toda sua extensão, por problemas alheios aos seus esforços. Mas não lhes assegura a permanência e o prosseguimento da escolaridade em todos os níveis de ensino (MANTOAN, 2011, p. 33).

Com a finalidade de oportunizar a permanência e o prosseguimento dos alunos, a formação inicial dos professores pode ser apontada como um dos fatores determinantes para que se efetive um ensino que contemple a educação especial dentro da perspectiva de uma educação inclusiva. Questões relacionadas à inclusão devem ser incorporadas ao currículo e problematizadas no ambiente acadêmico, oportunizando aos futuros professores conhecimentos teóricos e práticos sobre a temática e sobre eles, sua condição, e as múltiplas competências a serem desenvolvidas com foco voltado para a aprendizagem dos mesmos e seu desenvolvimento. Nesse sentido,

[...] um tema que requer intensa reflexão, diz respeito à reformulação do currículo de formação do educador, na pedagogia e nas licenciaturas, de maneira que esta formação contemple a heterogeneidade escolar presente em escolas que buscam tornarem-se inclusivas (BEYER, 2009, p. 79).

Quanto à necessidade dessa reformulação na formação inicial, há um direcionamento explícito na Resolução $\mathrm{n}^{\circ} 2$, de $1^{\circ}$ de julho de 2015 , que define as Diretrizes Curriculares na formação inicial em nível superior e formação continuada. A saber:

$\S 2^{\circ}$ Os cursos de formação deverão garantir nos currículos conteúdos específicos da respectiva área de conhecimento ou interdisciplinares, seus fundamentos e metodologias, bem como conteúdos relacionados aos fundamentos da educação, formação na área de políticas públicas e gestão da educação, seus fundamentos e metodologias, direitos humanos, diversidades étnico-racial, de gênero, sexual, religiosa, de faixa geracional, Língua
Brasileira de Sinais (Libras), educação especial e direitos educacionais de adolescentes e jovens em cumprimento de medidas socioeducativas (MEC, 2015, p. 11).

Ainda sobre essa questão e em consonância com o indicativo acima destaca-se o que já estava posto no Plano Nacional de Educação (PNE) em sua meta 13, estratégia 13.4 que ao discutir a melhoria nos cursos de pedagogia e das licenciaturas sugere que as instituições formadoras criem instrumentos próprios de avaliação cujos mecanismos permitam revisões e considerações quanto às necessidades reais da educação básica, permitindo aos:

[...] graduandos a aquisição das qualificações necessárias a conduzir o processo pedagógico de seus futuros alunos(as), combinando formação geral e específica com a prática didática, além da educação para as relações étnico-raciais, a diversidade e as necessidades das pessoas com deficiência (BRASIL, 2014, p. 76).

É importante salientar que incorporar as temáticas relacionadas à inclusão, sobretudo do público-alvo da educação especial, nos Projetos Pedagógicos dos Cursos, não se trata apenas de cumprir os dispositivos legais que a lei exige, mas, sobretudo, é a demonstração de um compromisso com a formação geral dos futuros educadores.

Os estudos relativos ao impacto dessas políticas nos currículos dos cursos e na formação dos professores são recentes. Entretanto, cabe considerar que a inserção de apenas uma disciplina não irá promover avanços significativos na formação dos professores para o ensino de alunos com necessidades educacionais especiais. É preciso ir além e possibilitar que os conhecimentos sobre as especificidades desses alunos sejam estudados, refletidos e pesquisados de maneira sistematizada, por diferentes disciplinas do curso (PEDROSO; CAMPOS; DUARTE, 2013, p. 43).

Uma vez inseridas nos cursos de formação, é possível inferir que as discussões sobre a educação especial, ocorridas em uma disciplina específica, perpassem toda a matriz curricular de modo transversal, sendo contempladas nos diferentes núcleos como temas de projetos pautados no tripé ensino, pesquisa e extensão.

Glat e Pletsch (2010), ao discutirem a formação de professores no contexto da política da educação inclusiva, afirmam que as instituições formadoras (com destaque para as universidades) devem atuar dentro das três dimensões constitutivas - ensino, pesquisa e extensão - a fim de contribuírem para a operacionalização das políticas inclusivas.

Como primeira vocação, elas apontam o ensino como essencial para a formação de docentes críticos de modo que estes não sejam meramente transmissores de conhecimento. A segunda esfera é a pesquisa, principalmente as chamadas aplicadas que podem atuar diretamente sobre a realidade. Por fim e não menos importante, está a extensão que visa responder às demandas da sociedade. A extensão

[...] projeta-se como um processo de inserção social consciente da universidade que implica em uma retroalimentação mútua entre a produção de conhecimento acadêmico e sua disseminação e concretização em práticas sociais. É na dimensão da extensão que se faz a tão necessária relação teoriaprática, que se manifesta em diversas formas: 
cursos, capacitações, seminários, consultorias, projetos aplicados e outros projetos desenvolvidos pela universidade em diferentes comunidades. (GLAT; PLETSCH, 2010, p. 352).

Nesse contexto em que a extensão se insere com ampla possibilidade de consolidar uma melhoria significativa na formação de docentes, a execução de projetos com temática relacionada à educação especial, na perspectiva inclusiva, pode constituir-se num caminho alternativo para implementar novas formas de conduzir os processos formativos para os licenciandos atuarem junto aos EPAEE, na rede de ensino nas diferentes modalidades da educação brasileira.

Segundo a Resolução ${ }^{\circ} 31$ / CONSUP /I FRO / 2017, em seus Art. $3^{\circ}$ e $4^{\circ}$, a extensão no Instituto Federal de Rondônia é considerada "[...] um processo educativo, cultural, social, científico e tecnológico que promove a interação entre as instituições, os segmentos sociais e o mundo do trabalho, com vistas ao desenvolvimento socioeconômico sustentável [...]" (IFRO, 2017, p. 1), articulando

[...] o Ensino e a Pesquisa de forma indissociável e representa efetivamente a troca de saberes e experiências realizadas permanentemente com a comunidade, da qual resulta um conhecimento e uma prática alinhados com a realidade local, regional e nacional.” (IFRO, 2017, p. 1).

Assim, este relato de experiência é fruto do projeto de extensão "O ensino de Química e a educação inclusiva: o desafio da formação docente", ocorrido no ano de 2017, fomentado pelo Edital $\mathrm{n}^{\circ}$ 19/2017/IFRO, e desenvolvido junto aos licenciandos cursistas da disciplina de Educação Inclusiva do curso de Licenciatura em Química, ofertada no $8^{\circ}$ período, cuja ementa apresentada no Projeto Pedagógico do Curso aborda:

[...] conceito histórico, princípios e objetivos; clientela e formas de atendimento. Política Nacional de Educação Inclusiva: estrutura, organização e legislação. Modalidades alternativas e abordagens educacionais na escola regular para os diferentes sujeitos: povos da floresta, negros, pessoas com deficiência (IFRO, 2009, p. 63).

Dessa forma, nessa perspectiva integradora entre o ensino, pesquisa e extensão o projeto teve como objetivo oportunizar conhecimento teórico aliado à prática pedagógica por meio da realização de oficinas, aos acadêmicos do curso de Licenciatura em Química, em especial aos matriculados na disciplina Educação Inclusiva, que resultou na produção de materiais pedagógicos destinados aos alunos da educação especial.

Os licenciandos executaram diferentes atividades, participando como ministrantes das oficinas pedagógicas realizadas em eventos promovidos no campus destinados à comunidade externa (público em geral), atuando como professores e pesquisadores nas intervenções pedagógicas executadas em escolas estaduais (futuro campo profissional) e nas instituições colaboradoras do projeto: a APAE (Associação de Pais e Amigos dos Excepcionais) e o Centro Municipal de Atendimento Educacional Especializado para Autismo.

$\mathrm{Na}$ sequência, apresenta-se a metodologia utilizada durante a execução do projeto, as contribuições, possibilidades, resultados, discussões e, por fim as considerações finais.

\section{Método}

Este relato de experiência é resultado de um estudo de abordagem qualitativa, na modalidade interventiva e descritiva que teve início a partir da oferta, no $8^{\mathrm{a}}$ período, da disciplina Educação Inclusiva quando a professora ministrante e os acadêmicos de Licenciatura em Química desenvolveram o projeto "O ensino de Química e a educação inclusiva: o desafio da formação docente", o qual foi implementado durante o primeiro e o segundo semestres do ano de 2017, no Instituto Federal de Educação, Ciência e Tecnologia de Rondônia - campus Ji-Paraná, submetido e aprovado em um Edital de Extensão. Suas ações ocorreram de modo indissociável, entrelaçando ensino, pesquisa e extensão.

A disciplina Educação Inclusiva não exige prérequisitos, essa flexibilidade permite que acadêmicos de semestres diferentes a cursem, contribuindo para heterogeneidade da turma. Considerando-se os dois semestres aludidos, foram matriculados na disciplina 40 alunos. Uma particularidade a ser apontada foi que embora o curso seja noturno a disciplina no primeiro semestre foi ministrada no período vespertino, após solicitação de alguns acadêmicos. Já no segundo semestre, as aulas ocorreram no turno noturno.

Assim que o projeto foi aprovado junto ao Departamento de Extensão do campus, a coordenadora e professora da disciplina conversou com os acadêmicos informando-os que algumas ações destinadas ao público externo seriam desenvolvidas por eles, e que outras específicas relacionadas ao ensino seriam trabalhadas durante as aulas.

Essa explicação e convite foram prontamente aceitos. Os acadêmicos demonstraram entusiasmo com a possibilidade das intervenções e da oferta das oficinas, pois em geral muitos questionamentos são levantados quando se trata da escolarização dos estudantes público-alvo da educação especial, entre esses se destacam: O que e como fazer? Como transpor as barreiras e incluir esses alunos de fato? Como vencer a insegurança na sala de aula?

Entre essas indagações uma em especial está diretamente ligada à área de formação dos acadêmicos envolvidos e das exigências inerentes ao futuro exercício da profissão: Como ensinar Química a alunos público-alvo da educação especial? Como garantir segurança nos laboratórios? Como explicar conceitos e teorias que exigem alto grau de abstração e complexidade? Como esclarecer as mudanças de temperatura e visuais que ocorrem em alguns processos? Esses questionamentos foram discutidos no decorrer dos seminários propostos e descritos nas etapas abaixo.

$\mathrm{Na}$ primeira etapa, os dois primeiros objetivos específicos do projeto consistiam em: a) discutir a educação inclusiva no ambiente educacional e b) distinguir o que é a educação especial numa perspectiva inclusiva identificando seus sujeitos, considerando o processo histórico à luz das teorias existentes e o respaldo legal. Ambos foram explicados aos discentes e em seguida transformados em uma primeira ação.

Para a realização da ação seguiram-se os passos metodológicos: primeiramente a professora abordou a 
temática utilizando dinâmicas, leitura de textos e discussões em grupo. Os conceitos de educação inclusiva $e$ os diferentes textos $^{1}$ foram lidos e discutidos em pequenos grupos. Esse procedimento pedagógico:

Consiste basicamente em distribuir temas de estudo iguais ou diferentes a grupos fixos ou variáveis, compostos de 3 a 5 alunos.[...] deve ser empregado eventualmente, conjugado com outros métodos de exposição ou de trabalho independente[...] A finalidade principal do trabalho em grupo é obter a cooperação dos alunos entre si na realização de uma tarefa (LIBÂNEO, 1994, p. 170).

O método de exposição foi utilizado pela professora que retomou os pontos principais esclarecendo a educação especial na perspectiva da educação inclusiva.

O terceiro objetivo consistia em discutir os temas: Transtorno Global do Desenvolvimento (TGD), com maior foco no Transtorno do Espectro Autista (TEA) e com destaque para Síndrome de Asperger; Deficiência Intelectual (DI) com ênfase para os estudantes com Síndrome de Down; Deficiência Visual (DV); Deficiência Auditiva (DA); Deficiência Física (DF); Deficiência Múltipla (DM) e Altas habilidades/Superdotação (AH/SD).

Para dinamizar a apresentação, acadêmicos do Curso de Licenciatura em Química se dividiram em grupos conforme afinidade existente, bem como consideraram o fato de morarem próximos (alguns eram residentes de outros municípios), o que facilitaria os contatos extra sala de aula para a realização de atividades externas quando necessário. Em seguida, os temas foram sorteados e foi proposta a realização de uma pesquisa bibliográfica sobre as temáticas, pois esta permite "[...] ao investigador a cobertura de uma gama de fenômenos muito mais ampla do que aquela que poderia pesquisar diretamente [...] a pesquisa bibliográfica também é indispensável nos estudos históricos" (GIL, 1999, p. 65). Estabeleceu-se que os assuntos seriam explicados numa perspectiva histórica, contemplando os conceitos existentes sobre a deficiência, os movimentos sociais que colaboraram para os avanços e retrocessos da temática no campo educacional e as tecnologias assistivas disponíveis na área da Química. Também foi realizada pesquisa de campo para verificar como o Atendimento Educacional estava sendo ofertado no município, além de levantarem uma situação problema detectada durante a pesquisa. Para o levantamento dos problemas, os alunos poderiam optar por realizarem uma entrevista com um gestor educacional, professores da sala regular de ensino ou do atendimento educacional especializado, ou apontarem um problema vivenciado ao longo do curso, existente na própria instituição, ou ainda reproduzir uma experiência já descrita na literatura.

Ao final dessa fase, os grupos apresentaram a proposta de uma oficina com a indicação de uma intervenção pedagógica sobre o tema estudado como uma possibilidade de superação de uma situação problema detectada durante a pesquisa e que, de preferência, estivesse diretamente relacionada ao ensino da Química.

O resultado da pesquisa inicial seria exposto sob a forma de seminários, as informações sistematizadas nos slides, seriam encaminhadas posteriormente ao email do professor/coordenador do projeto e aos demais participantes. Foi determinado que as dúvidas seriam sanadas após as apresentações.

Uma vez esclarecidos os questionamentos, os grupos deveriam exibir um filme ou um vídeo relacionado ao tema abordado no seminário. Após a exibição, um texto impresso (artigo científico, reportagem, trecho de um poema) seria entregue aos demais grupos e pontos relevantes do filme e do texto serviriam como desencadeadores, a fim de serem debatidos numa roda de conversa.

Ao longo dos semestres, com o intuito de promover uma melhor aprendizagem e aprofundamento das temáticas, especialistas foram convidados a ministrar palestras educativas aos participantes do projeto e aos demais acadêmicos do curso de Licenciatura em Química.

A segunda etapa, que se caracterizou pela proposição de execução de oficinas pedagógicas, contemplou o quarto objetivo específico do projeto, que visava à execução de oficinas pedagógicas com geração de materiais pedagógicos para o ensino da Química. Essas oficinas foram ministradas em dois eventos abertos tanto para a comunidade interna como externa, promovidos pelo campus. No primeiro semestre o evento selecionado foi o III Seminário de Ensino, Pesquisa e Extensão (SEPEX) e no segundo o V Day Software.

Para a execução dessa atividade, foi acordado entre os acadêmicos que os conteúdos teóricos abordados nos seminários seriam revisados $\mathrm{e}$ adequados a um tempo menor e expostos em forma de palestras. Em seguida, os materiais pedagógicos seriam confeccionados e encaminhados às instituições parceiras para as intervenções pedagógicas. Ao término, um questionário avaliativo sobre a atividade seria aplicado.

$\mathrm{Na}$ terceira e última etapa, foram realizadas as intervenções: escrita científica e apresentação dos resultados. Essa última etapa visou à promoção de um intercâmbio entre os acadêmicos participantes do projeto junto às instituições parceiras, a fím de que alguns produtos gerados nas oficinas fossem usados nas intervenções. Após a intervenção, a experiência deveria ser sistematizada em um artigo ou relato de experiência e apresentado a uma banca avaliadora. Os membros do Núcleo de Atendimento aos Estudantes com Necessidades Específicas (NAPNE) do IFRO foram convidados a avaliar os trabalhos.

\section{Resultados e Discussões}

O projeto inicial previa o desenvolvimento das seguintes ações abaixo descritas, algumas ocorreram na íntegra, entretanto foram necessárias algumas alterações ao longo do trabalho. 
Quadro 1 - Ações previstas no projeto.

\begin{tabular}{|l|l|}
\hline \multicolumn{1}{|c|}{ Ação prevista } & \multicolumn{1}{|c|}{ Público } \\
\hline $\begin{array}{l}\text { Oportunizar o conhecimento teórico dos temas: } \\
\text { Transtorno do Espectro Autista(TEA) e as } \\
\text { Deficiências: Intelectual Múltipla, Visual, Auditiva e } \\
\text { Altas habilidades/Superdotação. }\end{array}$ & Alunos da disciplina \\
\hline $\begin{array}{l}\text { Realização de três palestras educativas com os } \\
\text { temas: formação docente para os desafios da } \\
\text { educação inclusiva; acessibilidade como caminho } \\
\text { para a inclusão escolar e, a utilização de jogos como } \\
\text { proposta de aprendizagem para alunos surdos. }\end{array}$ & $\begin{array}{l}\text { Aluno da disciplina e do curso de } \\
\text { Licenciatura em Química }\end{array}$ \\
\hline $\begin{array}{l}\text { Oferta de seis oficinas pedagógicas. } \\
\text { Promoção de três intercâmbios para a realização das } \\
\text { intervenções pedagógicas. }\end{array}$ & $\begin{array}{l}\text { Alunos de escolas estaduais, da } \\
\text { APAE e Centro de Autismo }\end{array}$ \\
\hline $\begin{array}{l}\text { Escrita de artigos científicos e apresentação aos } \\
\text { avaliadores }\end{array}$ & Alunos matriculados na disciplina. \\
\hline
\end{tabular}

Fonte: Informações do projeto.

No decorrer da oferta da disciplina Educação Inclusiva, foram promovidas discussões referentes à educação inclusiva e em especial à modalidade educação especial prevista na Lei de Diretrizes e Bases da Educação Lei nº 9.394/1996.

$\mathrm{O}$ quanto antes compreenderem os diferentes grupos que compõem a educação brasileira, maiores as chances para a efetivação de uma educação inclusiva com sucesso. Cabe aos licenciandos incorporarem o princípio expresso pela Declaração de Salamanca que alerta para o fato de que as escolas:

[...] deveriam acomodar todas as crianças independentemente de suas condiç̃es físicas, intelectuais, sociais, emocionais, linguísticas ou outras. Aquelas deveriam incluir crianças deficientes e superdotadas, crianças de rua e que trabalham, crianças de origem remota ou de população nômade, crianças pertencentes a minorias linguísticas, étnicas ou culturais, e crianças de outros grupos desavantajados ou marginalizados. (UNESCO, 1998, p. 1).

A compreensão da Educação Especial na perspectiva inclusiva é extremamente necessária e convida os acadêmicos a uma reflexão mais profunda sobre seu papel social no exercício de sua profissão. Essas reflexões puderam ser notadas no decorrer das aulas, momento em que os alunos participaram ativamente, externando suas opiniões e questionamentos. Nessa perspectiva:

A formação dos professores e seu desenvolvimento profissional são condições necessárias para que se produzam, práticas integradoras positivas nas escolas. É muito difícil avançar no sentido das escolas inclusivas se os professores em seu conjunto, e não apenas os professores especialistas em educação especial, não adquirirem uma competência suficiente para ensinar a todos os alunos. Além disso, a formação tem uma estreita relação com sua atitude diante da diversidade do aluno. $\mathrm{O}$ professor, quando se sente pouco competente para facilitar a aprendizagem dos alunos com necessidades educativas especiais, tenderá a desenvolver expectativas mais negativas, que se traduzem em uma menor interação e menor atenção. $\mathrm{O}$ aluno, por sua vez, terá mais dificuldades para resolver as tarefas propostas, o que reforçará as expectativas negativas do professor. Essas considerações levam a afirmar que o modo mais seguro de melhorar as atitudes e as expectativas dos professores é desenvolver seu conhecimento das diversidades dos alunos e suas habilidades para ensinar-lhes. (COLLI; MARCHESI; PALACIOUS, 2004, p. 44).

No primeiro semestre, o fato de se ter mais acadêmicos matriculados permitiu que os debates fossem mais ricos. A redução de alunos no segundo semestre demandou uma alteração na metodologia adotada, os temas foram apresentados individualmente para que discussões fossem geradas. Percebeu-se o quanto o trabalho em pequenos grupos, enriquece a aprendizagem:

Trabalhar num grupo é diferente de fazer parte de um conjunto de pessoas, sendo fundamental a interação, o compartilhar, o respeito à singularidade, a habilidade de lidar com o outro em sua totalidade, incluindo suas emoções. Isso exige autonomia e maturidade, algo a ser construído paulatinamente com os alunos universitários, uma vez que não trazem esses atributos do ensino médio (ANASTASIOU; ALVES, 2005, p. 76).

Pode-se notar o envolvimento dos acadêmicos que conseguiram se organizar, definindo as tarefas e realizando as apresentações. Como tinham um roteiro a ser seguido, não houve desperdício de tempo e os seminários puderam ser concretizados dentro do cronograma previamente estabelecido.

Os seminários são muito utilizados junto aos acadêmicos da licenciatura, entretanto, para que eles ocorram de modo satisfatório é preciso, primeiro, que os licenciandos tenham se apropriado de como trabalhar em grupo de modo eficaz, "[...] os estudantes precisam ter clareza prévia dos diversos papéis que desenvolverão durante toda a dinâmica dos trabalhos" (ANASTASIOU; ALVES, 2005, p. 90), a partir do momento em que:

[...] um aluno ou um grupo de alunos fica encarregado de fazer uma pesquisa sobre determinado assunto. Em seguida, expõe o tema pesquisado para toda a classe. A utilização da técnica do seminário contribui para 0 desenvolvimento do espírito de pesquisa, levando o educando a coletar material para a análise e interpretação fazendo com que ele sistematize as informaç̃es coletadas para posterior exposição e transmissão (HAYDIT, 2011, p. 145).

$\mathrm{O}$ seminário exigiu dos participantes comprometimento e uma densa pesquisa bibliográfica. Sem dúvida, as possibilidades do ensino e da aprendizagem dos conteúdos de Química aos estudantes público-alvo da educação especial se constituem em desafio constante, tanto para o professor quanto para as pessoas com deficiência. A exemplo disso, destacaram-se os estudos de Razuck e Oliveira Neto (2015) e Resende Filho et al. (2013), que discutem a problemática da pessoa com deficiência visual, enquanto Marchi e Silva (2016) abordam sobre a formação do professor e o uso das tecnologias assistivas, além de Abraão et al. (2016), Campos e Lira (2017) que discutem a partir da Deficiência Intelectual.

Nesse viés, identifica-se na consulta aos Trabalhos de Conclusão de Curso (TCCs) elaborados no campus onde este trabalho se desenvolveu, três trabalhos voltados para a temática, são eles: Lopes e Ferreira $(2015 ; 2017)$ sobre deficiência auditiva e Silva Filho (2016) que discutiu a formação do professor para o trabalho com a deficiência visual.

Para o levantamento das situações problemas, quatro critérios foram adotados: alguns grupos realizaram uma entrevista informal realizada nas escolas públicas (ou junto ao diretor, professor da classe regular ou da sala de recurso); sugestões apontadas pela APAE e Centro de Autismo 
(instituições parceiras) foram trazidas pela coordenadora do projeto; um grupo buscou apoio de uma orientanda que estava desenvolvendo um Trabalho de Conclusão de Curso (TCC) da própria instituição, orientada pela coordenadora do projeto e outro grupo analisou uma situação vivenciada no próprio campus.

$\mathrm{O}$ fato de os alunos estarem cursando as disciplinas de estágio ou serem do Programa Institucional de Bolsas de Iniciação à Docência (PIBID) facilitou o diálogo nas escolas, demandando propostas intervencionistas possíveis de serem aplicadas e reaplicadas em diferentes contextos.

Mesmo diante de um roteiro definido, algumas apresentações surpreenderam. Cabe aqui o relato do grupo da Deficiência Visual. Durante o seminário foi apresentada uma entrevista com um aluno cego mestrando, que relatou seu processo de escolarização. A entrevista foi concedida para fins pedagógicos. Outra surpresa ficou por conta da Deficiência Física que levou os alunos a vivenciarem os transtornos relativos à acessibilidade que um cadeirante poderia enfrentar ao se locomover pelo campus.

Porém, a maior dificuldade foi enfrentada pelos alunos que explicaram a Deficiência Múltipla. Esse grupo em particular não conseguiu formular uma proposta interventiva. Como alternativa, eles confeccionaram uma maquete de um ambiente adaptado, e seus integrantes foram inseridos nos outros grupos para auxiliarem nas demais oficinas.

Outro recurso adotado foi a exibição de filmes que abordassem as temáticas discutidas. Os trabalhos de Nozu et al., Marchesin, Santos e Noro, e Christofoletti (2009; 2017; 2013; 2009) apontam a eficácia desse recurso, sendo utilizado no ensino superior, contemplando diferentes áreas de conhecimento. A pesquisa desenvolvida por Christofoletti (2009, p. 612) revela que:

O questionário aplicado aos 55 docentes de 11 diferentes cursos universitários permitiu uma compreensão mais detalhada do uso do cinema em situação de ensino por esses sujeitos. Percebeu-se, por exemplo, que os docentes recorrem com alguma naturalidade e constância à exibição de filmes em sala de aula. O cinema é um recurso aceito pela maioria dos alunos, conforme relato dos docentes, e ele é usado geralmente no ambiente escolar, durante o horário das aulas.

Segundo Marchesin (2017, p. 104) seu uso:

[...] oferece a experimentação de diferentes visões de mundo, além daqueles da órbita pessoal. A suspensão proporcionada pelo filme permite uma forma de descobrir essas dimensões sociais de forma menos exaustiva e diferenciada, proporcionando maior empatia pela reflexão que será posta.

Essa tarefa exigiu cautela entre os grupos. Não bastava apenas a exibição, era necessário que esta desencadeasse uma sólida discussão. Desse modo, o filme foi assistido com antecedência e coube aos grupos decidirem se o mesmo seria exibido na íntegra ou trechos selecionados, além de organizarem perguntas desencadeadoras para a discussão na roda de conversa. Para facilitar esse momento, um texto complementar foi disponibilizado a fim de fundamentar os pontos essenciais.
Alguns grupos optaram por apresentar pequenos vídeos disponibilizados na internet. Os filmes exibidos foram: O guardião de memórias, O filho eterno, Uma viagem inesperada, Os filhos do silêncio, Vermelho como o céu e Os intocáveis.

Após os seminários, o próximo passo foi a organização e execução das oficinas pedagógicas que, para efeito de análise neste trabalho serão denominados OP1, OP2, OP3, OP4, OP5, OP6, OP7, OP8, OP9. Essas oficinas foram conduzidas pelos acadêmicos da licenciatura, pela coordenadora do projeto e colaboradores, sendo 06 abertas ao público interno e externo inscritos nos eventos, uma realizada em sala de aula e duas junto às associações parceiras. $\mathrm{O}$ quadro representa as oficinas ofertadas:

Quadro 2 - Título das oficinas.

\begin{tabular}{|c|c|c|c|}
\hline $\begin{array}{l}\mathbf{N}^{\circ} \text { de } \\
\text { Ordem }\end{array}$ & Título da Oficina & \begin{tabular}{|c|}
$\begin{array}{c}\text { Evento em que foi } \\
\text { ministrada }\end{array}$ \\
\end{tabular} & $\begin{array}{r}\text { Temática } \\
\text { Abordada }\end{array}$ \\
\hline OP1 & $\begin{array}{l}\text { Deficiência Intelectual- O uso de } \\
\text { jogo lúdico na abordagem de } \\
\text { cuidados pessoais com alunos com } \\
\text { Síndrome de Down. }\end{array}$ & Sala de aula & DI \\
\hline OP2 & $\begin{array}{l}\text { Confecção de Baralho Químico } \\
\text { como auxílio aos surdos para } \\
\text { aprendizagem da Tabela Periódica }\end{array}$ & III SEPEX & DV \\
\hline OP3 & $\begin{array}{l}\text { Desenvolvimento de estratégias } \\
\text { pedagógicas para trabalho com } \\
\text { autistas. }\end{array}$ & III SEPEX & TEA \\
\hline OP4 & $\begin{array}{l}\text { Acessibilidade acadêmica - Bancada } \\
\text { laboratorial para cadeirantes }\end{array}$ & III SEPEX & DF \\
\hline OP5 & $\begin{array}{l}\text { Habilidades Teórico-químicas na } \\
\text { teoria, criatividade e cálculo }\end{array}$ & III SEPEX & $\mathrm{AH} / \mathrm{SD}$ \\
\hline OP6 & $\begin{array}{l}\text { Grafia Química Braille - Construção } \\
\text { da Tabela Periódica para ensinar } \\
\text { conceitos dos elementos Químicos } \\
\text { para alunos cegos ou de baixa visão. }\end{array}$ & III SEPEX & DV \\
\hline OP7 & A Casa Química & APAE & DI \\
\hline OP8 & $\begin{array}{l}\text { Escola de Pai: Construção de } \\
\text { Materiais para crianças autistas }\end{array}$ & V Day Software & TEA \\
\hline OP9 & $\begin{array}{l}\text { Elaboração de Livros Táteis para a } \\
\text { sala de Linguagens }\end{array}$ & Centro de Autismo & TEA \\
\hline
\end{tabular}

Fonte: Elaborado pelos autores com base na proposta do projeto.

O planejamento adotado contemplou, no primeiro momento, uma palestra educativa, seguida da proposta de sensibilização ou elaboração de materiais pedagógicos e a avaliação da oficina.

Algumas oficinas apresentaram particularidades, como é o caso da OP1 e OP5, que oportunizaram aos participantes brincarem com os jogos previamente elaborados por seus proponentes. Desenvolvida em sala de aula, a OP1 teve como proposta que os participantes jogassem um dominó educativo, previamente elaborado, com foco nos cuidados pessoais que devem ser enfatizados junto aos alunos com deficiência Intelectual. A intenção era mostrar que esse jogo poderia ser amplamente explorado junto aos alunos com Síndrome de Down.

O jogo explorado na OP5 visava trabalhar os conteúdos de Química de um modo mais avançado, incentivando a compreensão do conteúdo e sensibilizando os integrantes quanto às diferentes habilidades demonstradas pelo ser humano, conforme ilustra a (Imagem 1). O grupo procurou desmistificar a ideia recorrente no ambiente escolar que sugere que alunos com Altas Habilidades/Superdotação não precisam ser incentivados. 
Figura 1 - Jogo desenvolvido sendo jogado pelos participantes da Oficina.

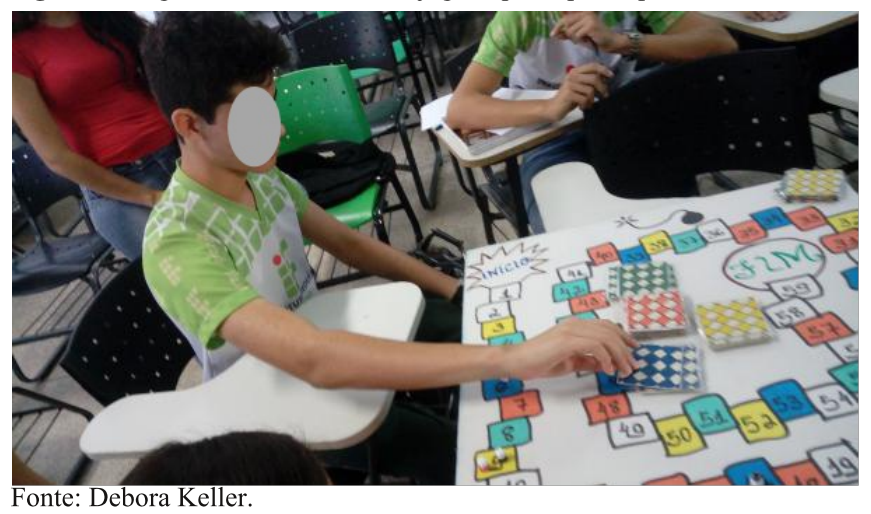

Dentre as oficinas que trabalharam a sensibilização, estava a OP4, que abordou a necessidade da acessibilidade em diferentes espaços educativos e demais setores da sociedade. Os oficineiros discutiram as dificuldades de inclusão do campus.

As OP3, OP8 e OP9 foram demandas pelo Centro Municipal de Atendimento Educacional Especializado para Autismo e envolveram a construção de materiais pedagógicos específicos tais como: skates, mobiliários para cozinha e livros táteis.

Restrita aos pais e colaboradores do centro, a OP9 teve como objetivo confeccionar os livros táteis utilizados na sala de linguagem. A OP8 contou com um público misto (público em geral, alunos do projeto, professores e pais do centro). Nessa oficina, foram construídos mobiliários de uma cozinha adaptados ao tamanho das crianças e um meio de transporte terrestre (um trem). Esses mobiliários foram inseridos na troca dos temas utilizados nas salas do centro e no transporte das crianças até a sala. Os responsáveis por essa inserção foram os professores e pais durante o acompanhamento diário.

A realização das OP8 e OP9 permitiu a inclusão dos pais dos alunos frequentadores do centro. Além de confeccionarem os materiais propostos, eles puderam compreender a importância desses materiais como auxiliadores da aprendizagem dos filhos (Imagens 2 e 3).

Figura 2 - Livros produzidos.

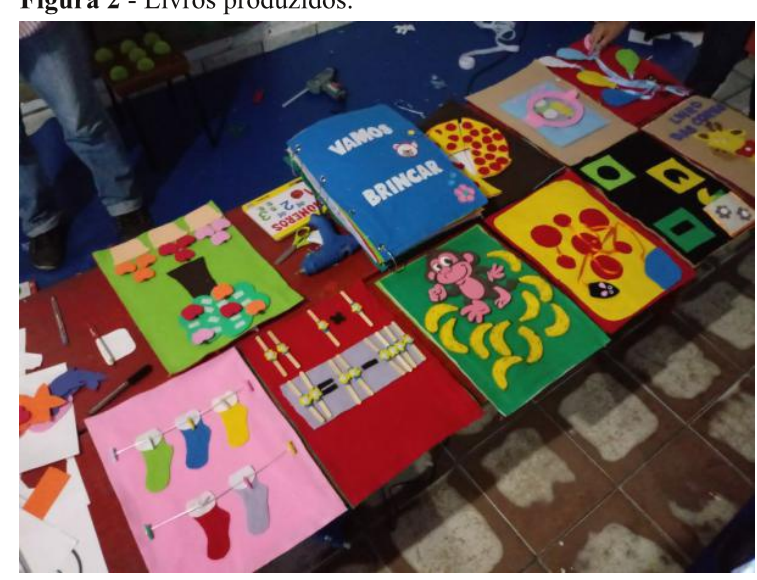

Fonte: Acervo pessoal.

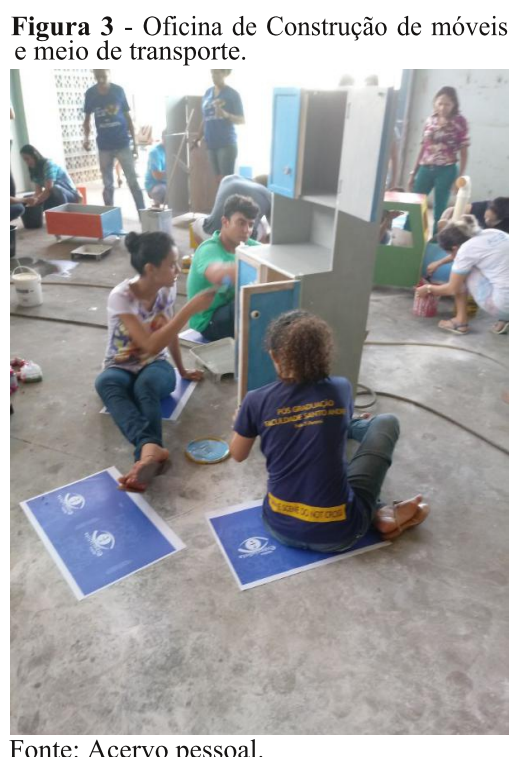

Fonte: Acervo pessoal.

A OP3 foi estendida à comunidade em geral e teve como objetivo construir skates adaptados. Esse recurso é utilizado junto às crianças a fim de trabalhar o equilíbrio e a força motora. Pais e alunos do curso utilizaram esses skates durante uma intervenção pedagógica realizada no Centro de Autismo (Imagem 4).

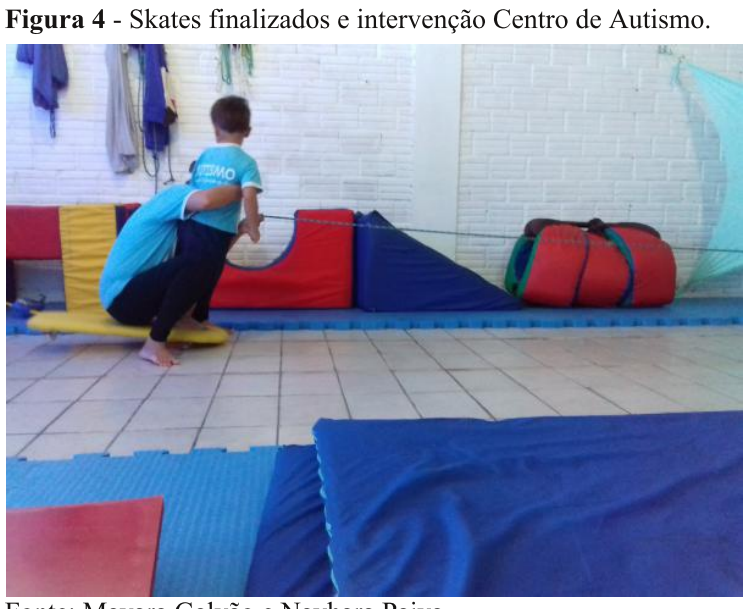

Fonte: Mayara Galvão e Nayhara Paiva.

O grupo que trabalhou com o tema Deficiência Visual desenvolveu duas atividades envolvendo diretamente o ensino da Química. Durante a OP6, os oficineiros trabalharam a escrita em Braile, ensinando o uso do reglete aos participantes. A segunda atividade resultou na construção de modelos atômicos químicos adaptados que oportunizaram uma intervenção junto a um aluno com baixa visão. Essa ação ficou restrita a três acadêmicos que se sensibilizaram diante das dificuldades enfrentadas por um aluno matriculado na rede regular de ensino. O obstáculo os motivou a construírem modelos que pudessem ser explorados pelo aluno.

A intervenção foi realizada na escola (Imagem 5), no contraturno, sendo acompanhada pela coordenadora do projeto, orientadora educacional, professora da sala de recursos e pelos licenciandos. 
Figura 5 - Intervenção pedagógica.

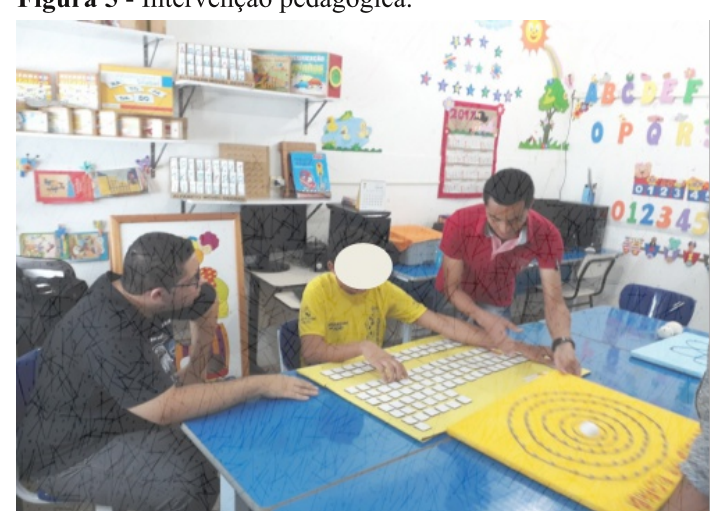

Fonte: Weder Martins.

O material consiste num modelo, em planta baixa, de uma casa impressa em papel panamá. Esse modelo foi disposto no chão para melhor visualização. No ambiente onde ocorreu a palestra, foram dispostos vasilhames vazios de produtos químicos, que deveriam ser armazenados nos cômodos da casa de maneira adequada pelo participante no decorrer do jogo.

A palestra preparada continha informações sobre produtos químicos, seus perigos e a correta utilização, bem como perguntas específicas, tais como: podemos beber produtos coloridos contidos nos frascos de desinfetantes? Podemos cheirar os produtos?

Por ser um jogo interativo, no decorrer do processo os alunos esclareceram dúvidas, participando ativamente, indicando se as informações prestadas na palestra são verdadeiras ou falsas. De acordo com as informações prestadas pelo palestrante, o participante escolhe onde alocar o produto. Após guardá-lo no cômodo escolhido, os demais acenam se a decisão foi acertada, ou não. Caso a escolha não tenha sido assertiva, nova chance é dada. Essa opção deve-se ao fato de que o interessante não é o vencer, mas sim o incentivo à participação e à compreensão do conteúdo requerido.

Tão logo o material foi finalizado, agendou-se uma visita à APAE para o desenvolvimento da atividade (Imagem 6). A aceitação do jogo pelos alunos superou as expectativas. A intervenção pedagógica foi acompanhada pelos professores da instituição parceira e pela coordenadora do projeto.

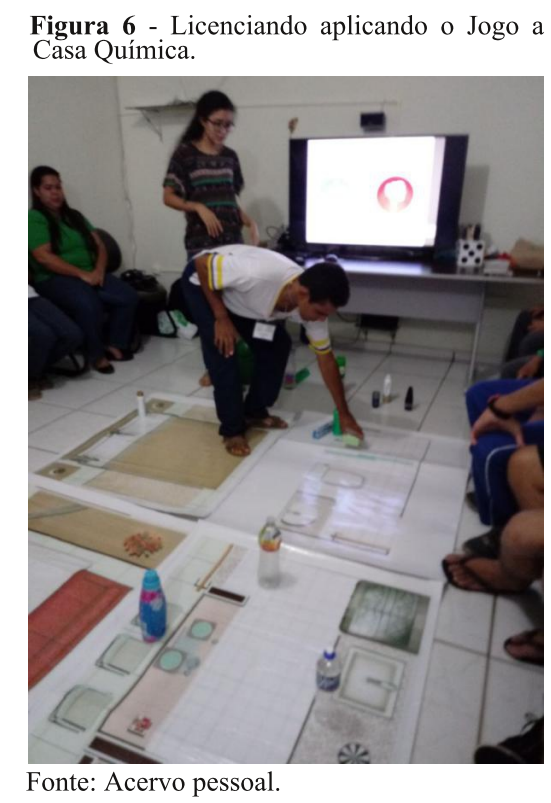

Dentre outras ações previstas, estavam as palestras educativas. Ao todo foram ministradas quatro, abordando os seguintes temas: A inclusão do TEA no ambiente educativo, Acessibilidade como caminho para a inclusão escolar (realizada em dois momentos) e A importância dos jogos no ensino da tabela periódica para os alunos surdos.

O quadro 4 sistematiza os principais produtos gerados ao longo das oficinas.

foi desenvolvida em sala de aula contando com uma carga horária maior. Optou-se pela construção de um jogo interativo pedagógico chamado "A Casa Química".

Em relação aos alunos com deficiência intelectual, o
ensino de química é ainda mais desafiador, uma vez
que, dependendo do grau de comprometimento
cognitivo, o aluno pode ter a sua capacidade de
buscar explicações lógicas e desenvolver posturas
críticas limitada, dificultando a construção de
modelos para os conceitos abstratos da química.

Em relação aos alunos com deficiência intelectual, o
ensino de química é ainda mais desafiador, uma vez
que, dependendo do grau de comprometimento
cognitivo, o aluno pode ter a sua capacidade de
buscar explicações lógicas e desenvolver posturas
críticas limitada, dificultando a construção de
modelos para os conceitos abstratos da química.

Em relação aos alunos com deficiência intelectual, o
ensino de química é ainda mais desafiador, uma vez
que, dependendo do grau de comprometimento
cognitivo, o aluno pode ter a sua capacidade de
buscar explicações lógicas e desenvolver posturas
críticas limitada, dificultando a construção de
modelos para os conceitos abstratos da química.

Em relação aos alunos com deficiência intelectual, o
ensino de química é ainda mais desafiador, uma vez
que, dependendo do grau de comprometimento
cognitivo, o aluno pode ter a sua capacidade de
buscar explicações lógicas e desenvolver posturas
críticas limitada, dificultando a construção de
modelos para os conceitos abstratos da química.

Em relação aos alunos com deficiência intelectual, o
ensino de química é ainda mais desafiador, uma vez
que, dependendo do grau de comprometimento
cognitivo, o aluno pode ter a sua capacidade de
buscar explicações lógicas e desenvolver posturas
críticas limitada, dificultando a construção de
modelos para os conceitos abstratos da química.

Em relação aos alunos com deficiência intelectual, o
ensino de química é ainda mais desafiador, uma vez
que, dependendo do grau de comprometimento
cognitivo, o aluno pode ter a sua capacidade de
buscar explicações lógicas e desenvolver posturas
críticas limitada, dificultando a construção de
modelos para os conceitos abstratos da química.

Para alcançar o objetivo proposto, a atividade

[...] a fim de atender no jogo todas as dúvidas por
eles apresentadas; estas iam desde a compreensão quanto a escolha de fontes coloridas nas cartas e pontos em destaque no baralho).

No decorrer da oficina, as cartas foram grupo ao qual seriam destinados. Na escola, ocorreu a intérprete do grupo, pelos licenciandos (integrantes do grupo) e pela coordenadora do projeto. mais complexas. A demanda foi apresentada pela aborda do municipio que solicitou aos licenciandos a os cuidados necessários para a segurança dos alunos fato de que acidentes domésticos poderiam ser evitados. com o ensino da química a ser trabalhado numa proposta contextualizada, com o propósito de que os conhecimentos adquiridos pudessem ser vivenciados no cotidiano. Segundo os autores Abraão et al. (2016, p. 2):

A OP2 reproduziu um baralho químico TCC, que foi destinado a alunos com deficiência auditiva (surdos) matriculados na rede estadual de esclarecidos quanto a informações e detalhes que deveriam constar e serem considerados. Em seu particularidades foram apresentadas pelos discentes enquanto desenvolviam seu trabalho e que precisaram porque cor do baralho era diferente da tabela, , 
Quadro 3 - Produto das oficinas

\begin{tabular}{|c|c|c|c|}
\hline $\begin{array}{c}\mathbf{N}^{\circ} \text { de } \\
\text { Ordem }\end{array}$ & Título da Oficina & Produto Gerado & $\begin{array}{c}\text { Temática } \\
\text { Abordada }\end{array}$ \\
\hline OP1 & $\begin{array}{l}\text { Deficiência Intelectual- O uso de } \\
\text { jogo lúdico na abordagem de } \\
\text { cuidados pessoais com alunos com } \\
\text { Síndrome de Down. }\end{array}$ & $\begin{array}{l}\text { Dominó } \\
\text { pedagógico }\end{array}$ & DI \\
\hline OP2 & $\begin{array}{l}\text { Confecção de Baralho Químico } \\
\text { como auxílio aos surdos para a } \\
\text { aprendizagem da Tabela Periódica. }\end{array}$ & $\begin{array}{l}\text { Reprodução de um } \\
\text { baralho }\end{array}$ & DV \\
\hline OP3 & $\begin{array}{l}\text { Desenvolvimento de estratégias } \\
\text { pedagógicas para trabalho com } \\
\text { autistas. }\end{array}$ & Skates adaptados & TEA \\
\hline OP5 & $\begin{array}{l}\text { Habilidades Teórico-químicas na } \\
\text { teoria, criatividade e cálculo. }\end{array}$ & Jogo pedagógico & $\mathrm{AH} / \mathrm{SD}$ \\
\hline OP7 & A Casa Química. & Jogo pedagógico & DI \\
\hline OP8 & $\begin{array}{l}\text { Escola de Pais: Construção de } \\
\text { Materiais para crianças autistas. }\end{array}$ & $\begin{array}{l}\text { Móveis para } \\
\text { cozinha e um trem }\end{array}$ & TEA \\
\hline OP9 & $\begin{array}{l}\text { Elaboração de Livros Táteis para a } \\
\text { sala de Linguagens. }\end{array}$ & Livros táteis & TEA \\
\hline
\end{tabular}

Fonte: Elaborado pelos autores.

Por fim, a última atividade foi a elaboração dos artigos pelos acadêmicos participantes do projeto e apresentação à banca avaliadora. Para a escrita, os licenciandos poderiam escolher entre as opções: escrever sobre a contribuição das aulas, enfocando o ensino recebido sobre os temas, destacar a ação extensionista realizada nas oficinas ou incorporar as duas opções anteriores em um único texto.

Os acadêmicos tiveram um curto período para escreverem seus textos antes dos mesmos serem avaliados. Diante dessa situação, a coordenadora informou previamente aos avaliadores que erros poderiam ser identificados (embasamento teórico sem as devidas referências, discussão inconsistente entre outros) e que as sugestões apontadas seriam anotadas e, caso os acadêmicos se interessassem por publicar posteriormente, a escrita seria revisada.

Os avaliadores eram integrantes do NAPNE. No dia agendado, eles se dirigiram à sala de aula para assistirem as apresentações, cada trabalho foi avaliado por um único representante. Durante a exposição, os acadêmicos envolvidos no trabalho apresentavam tanto ao avaliador como aos demais licenciandos e colaboradores do projeto. Assim que a apresentação era encerrada, as considerações sobre o trabalho eram destacadas.

Dentre os artigos elaborados, alguns foram apresentados em eventos sem publicação em anais, com exceção da atividade "A casa química" que foi publicada nos Anais do III SILLIC (BENTES, 2019).

\section{Conclusões}

Ao chegar ao fim deste relato, constata-se que o projeto "O ensino de química e a educação inclusiva: o desafio da formação docente" alcançou os objetivos e as metas inicialmente delineadas, constituindo-se como um importante instrumento na capacitação e formação de futuros professores.

Os dois primeiros objetivos: discutir a educação inclusiva no ambiente educacional e distinguir o que é a educação especial numa perspectiva inclusiva, identificando seus sujeitos, foram trabalhados ao longo da disciplina Educação Inclusiva numa compreensão histórico-crítica.
Diferentes textos e metodologias foram utilizados com o intuito de que o ensino ofertado aos acadêmicos proporcionasse não apenas a instrumentalização e as competências técnicas específicas inerentes à habilitação do professor de química, mas permitisse ao licenciando uma ampla visão sobre a educação e seu papel social e ético junto aos grupos minoritários e excluídos historicamente, como é o caso dos alunos público-alvo da educação especial.

Propor espaços para aprofundamento do estudo das deficiências: DV, DI, DA, DF e das AH/SD, e TEA por meio dos seminários e oficinas pedagógicas, ampliou a visão dos participantes quanto às possibilidades de atuação nas salas de aula e na urgência de práticas pedagógicas que consolidem uma aprendizagem significativa aos educandos.

Ensinar a química e incluir o aluno nas aulas é responsabilidade pessoal do professor, pois a inclusão não deve ser imputada e se restringir a professores especializados, intérpretes, cuidadores ou núcleos específicos, o que não significa que o suporte vindo desses profissionais e demais setores da escola deva ser desconsiderado, aliás, deve ser aproveitado ao máximo, permitindo a troca de saberes, tão benéfica a todos.

A realização das oficinas previstas no quarto objetivo, a construção dos materiais pedagógicos e a ações interventivas foram riquíssimas e forneceram um grande aprendizado aos envolvidos. Um fato que contribuiu para que todas as intervenções fossem realizadas foi a disciplina do primeiro semestre ter sido ofertada à tarde, essa particularidade facilitou a pesquisa e o acesso dos estudantes às instituições que geralmente atendem durante o dia.

$\mathrm{O}$ ensino, a pesquisa e a extensão foram fortemente explorados exigindo comprometimento dos participantes. A disseminação do conhecimento elaborado na academia e o requerido pelas diferentes realidades encontradas junto ao público externo estreitaram os laços entre a instituição formadora e as associações parceiras.

Quanto à exigência da elaboração de artigos ao final do projeto, é possível afirmar que as experiências vivenciadas pelos acadêmicos os instigaram a produzirem conhecimento e a refletirem quanto às responsabilidades que o exercício do magistério requer. A formação não se esgota na licenciatura, esse é o primeiro passo dentro de tantos outros que marcarão a caminhada do profissional.

Por fim conclui-se que as instituições formadoras de professores devem zelar pela elaboração de um currículo que contemple a diversidade, que discuta a educação especial de um modo interdisciplinar e que fomente a participação de seus licenciados em projetos sociais, de modo que os conhecimentos adquiridos façam a diferença para os que mais necessitam.

\section{Notas:}

1 Mantoan (2011), Lei de Diretrizes e Bases da Educação (1996), Política Nacional de Educacão Especial na Perspectiva da Educação Inclusiva (2008), Educar na Diversidade (2006), A Educação Especial na Perspectiva da Inclusão Escolar (2010), Plano Nacional de Educação (2014), Lei Brasileira de Inclusão da Pessoa com Deficiência (2015). 


\section{Referências}

ABRAÃO, J. S. et al. Educação inclusiva e ensino de Química: estratégias de aprendizagem para o ensino de estequiometria a alunos com deficiência intelectual. In: JORNADA CIENTÍFICA E TECNOLÓGICA DO IFSULDEMINAS. 8. SIMPÓSIO DE PÓS-GRADUAÇÃO. 5. Passos, 2016. Anais... Passos: IFSULDEMINAS, 2016. Disponível

em:<https://jornada.ifsuldeminas.edu.br/index.php/jcpas/jsp as/Sched

Conf/presentations.> Acesso em: 08 set. 2018.

ANASTASIOU, L. G. C.; ALVES, L. P. Estratégias de ensinagem. In: ANASTASIOU, L. G. C.; ALVES, L. P. (org.) Processos de ensinagem na universidade: pressupostos para as estratégias de trabalho em aula. 5. ed. Joinvile: UNIVILLE, 2005.

BENTES, P. A. et al. A casa química: Uma ação de intervenção pedagógica na APAE de Ji-Paraná. South American Journal of Basic Education, Technical and Technological, Rio Branco, v.6, suplemento n.4(Anais do III SILLIC), p. 262-278. 2019. Disponível em:

$<$ http://revistas.ufac.br/revista/index.php/SAJEBTT/issue/vi ewIssue/124/2http://revistas.ufac.br/revista/index.php/SAJE BTT/issue/viewIssue/124/222>. Acesso em: 08 abr. 2019.

BEYER, H. O. O projeto da educação inclusiva: perspectivas e princípios de implementação. In: JESUS, D. M.; BAPTISTA, C. R.; BARRETO, M. A. S. C. Inclusão e práticas pedagógicas e trajetórias de pesquisa. 2 . ed. Porto Alegre: Mediação, 2009. p. 75-81.

BRASIL. Constituição da República Federativa do Brasil, de 5 de outubro de 1988.Brasília, DF: Senado Federal, 1988.

BRASIL. Lei Federal nº 9.394 de 20 de dezembro de 1996 Lei de Diretrizes e Bases da Educação Nacional. Diário Oficial [da] República Federativa do Brasil, Brasília, DF, 23 dez. 1996. Disponível em: <

http://www.planalto.gov.br/ccivil

_03/leis/L9394.htm>. Acesso em: 20 maio 2018.

BRASIL. Plano Nacional de Educação 2014-2024 [recurso eletrônico]: Lei $\mathbf{n}^{\mathbf{0}} \mathbf{1 3 . 0 0 5}$, de 25 de junho de 2014, que aprova o Plano Nacional de Educação (PNE) e dá outras providências. Brasília: Câmara dos Deputados, Edições Câmara, 2014.

BRASIL. Ministério da Educação. Secretaria da Educação Especial. Política Nacional de Educação na Perspectiva da Educação Inclusiva. Brasília, DF, 2008. Disponível em: $<$ http://portal.mec.gov.br/arquivos/pdf/politicaeducespecial. pdf.> Acesso em: 10 abr. 2018

BRASIL. Lei ${ }^{\circ} 8.069$, de 13 de julho de 1990. Estatuto da Criança e do Adolescente. Diário Oficial [da] República Federativa do Brasil, Brasília, DF, 27 set. 1990. Disponível em:

$<$ http://www.planalto.gov.br/ccivil_03/LEIS/L8069.htm. Acesso em: 20 maio 2018.

BRASIL. Congresso Nacional. Lei 13.146 De 06 de julho de 2015. Institui a lei Brasileira de Inclusão da Pessoa com Deficiência (Estatuto da Pessoa com Deficiência. Brasília, DF: Casa Civil, 2015. Disponível em:

$<$ www.planalto.gov.br/ccivil 03/ ato2015-

2018/2015/lei/113146.htm>. Ācesso em: 30 abr. 2017.

CAMPOS, S. V.; LIRA, A. L. Metodologias alternativas para o ensino da Química aos deficientes intelectuais. In: CONGRESSSO NACIONAL DE EDUCAÇÃO
(CONEDU). 4., 2017, João Pessoa. Anais... Campina Grande: Realize, v. 1, 2017. Disponível em:

$<$ http://www.editorarealize.com.br/revistas/conedu/trabalhos /TRABALHO

EV073_MD4_SA16_ID2881_11092017182850.pdf>. Âcesso em: 20 out. $20 \overline{18}$.

COLL, C.; MARCHESI, A. ; PALACIUS, J.

Desenvolvimento psicológico e educação. 2. ed. Porto Alegre: Artmed, 2004.

CHRISTOFOLETTI, R. Filmes na sala de aula: recurso didático, abordagem pedagógica ou recreação? Educação, Santa Maria, v. 34, n. 3, p. 603-16, set./dez. 2009.

Disponível em: $<$ https://periodicos.ufsm.br/reveducacao $>$. Acesso em: 20 out. 2018.

FERREIRA, R. D. F. Baralho químico: o lúdico como auxílio no ensino de Química para surdos. 2017. 32 p.

Trabalho de Conclusão de Curso (Licenciatura em Química)

- Instituto Federal de Rondônia, Campus Ji-Paraná, Ji-

Paraná, 2017.

GLAT, R.; PLETSCH, M. D. O papel da universidade no contexto da política de Educação Inclusiva: reflexões sobre a formação de recursos humanos e a produção de conhecimento. Revista Educação Especial, Santa Maria, v. 23, n. 38, p. 345-356, set./dez. 2010. Disponível em: $<$ http://www.ufsm.br/revistaeducacaoespecial.> Acesso em: 20 out. 2018.

GIL, A. C. Métodos e Técnicas de Pesquisa social. 5. ed. São Paulo: Atlas, 1999.

HAYDT, R. C. C. Curso de didática geral. 1. ed. São Paulo: Ática, 2011.

IFRO. Instituto Federal de Rondônia. Projeto Pedagógico: curso de Licenciatura em Química. Ji-Paraná: IFRO, 2009.

IFRO. Instituto Federal de Rondônia. Conselho Superior. Resolução n⿳31 de 30 de maio de 2017. Regulamento de Extensão do IFRO. Porto Velho: IFRO, 2017.

IFRO. Instituto Federal de Rondônia. Campus Ji-Paraná. Edital $n^{\circ} 19$ de 23 de março de 2017. Ji-Paraná: CGAB, 2017.

LIBÂNEO. José Carlos. Didática. São Paulo: Cortez,1994

LOPES, C. B. A utilização de jogos como proposta de aprendizagem no estudo dos símbolos químicos da tabela periódica para alunos surdos. 2015.53 p. Trabalho de Conclusão de Curso (Licenciatura em Química) - Instituto Federal de Rondônia, Campus Ji-Paraná, Ji-Paraná, 2015.

MANTOAN, M. T. E. Inclusão escolar: caminhos, descaminhos, desafios, perspectivas. In: MANTOAN, M. T. E. (org.). $O$ desafio das diferenças nas escolas. 4. ed. Petrópolis, RJ: Vozes, 2011

MARCHESIN, V. R. O uso do cinema em sala de aula. In: SIMPÓSIO ESTADUAL DE FORMAÇÃO DE PROFESSORES DE SOCIOLOGIA DO PARANÁ, 7. ENCONTRO DO PIBID DE CIÊNCIAS SOCIAIS DA REGIÃO SUL. 5. 2017, Londrina. Anais... Londrina: UEL, 2017. Disponível em: <http://www.uel.br /projetos/lenpes/pages/arquivos/ANAIS\%20Simposio $\% 20$ Es tadual $\% 20 \mathrm{e} \% 20$ Encontro $\% 20$ PIBID $\% 202017$.pdf $>$. Acesso em: 20 out. 2018.

MARCHI, M. I.; SILVA, T. N. C. Formação continuada de professores: buscando melhorar e facilitar o ensino para deficientes visuais por meio de tecnologias assistivas.

Revista de Educação Especial, Santa Maria, v. 29, n. 55, p. 
457-70, maio/ago. 2016. Disponível em:

$<$ http://www.ufsm.br/revistaeducacaoespecial $>$. Acesso em: 20 out. 2018 .

MEC. Conselho Nacional da Educação. Resolução n ${ }^{\circ}$ 2, de $1^{\circ}$ de julho de 2015. Diário Oficial [da] República

Federativa do Brasil. Brasília, DF, 2 jul. 2015. Disponível em: <http://portal.mec.gov.br/docman/agosto-2017pdf/70431-res-cne-cp-002-03072015-pdf/file>. Acesso em: 10 set. 2018.

NOZU, W. C. S. et al. O filme como pretexto para discussão da inclusão escolar: relato de experiências. In: CONGRESSO BRASILEIRO MULTIDISCIPLINAR DE EDUCAÇÃO ESPECIAL. 5., 2009, Londrina. Anais... Londrina: UEL, 2009. Disponível em: $<$ http://www.uel.br/eventos/congressomultidisciplinar/pa ges/arquivos /anais/2009/252.pdf>. Acesso em: 20 out. 2018.

PEDROSO, C. C. A.; CAMPOS, J. A. P. P.; DUARTE, M. Formação de professores e educação inclusiva: análise das matrizes curriculares dos cursos de licenciatura. Educação Unisinos, São Leopoldo, v.17, n. 1, p. 40-47, jan./abr. 2013. Disponível em:

$<$ http://revistas.unisinos.br/index.php/educacao/article/view/ edu.2013.171.

05/1411>. Acesso em: 20 out. 2018.

RAZUCK, R. C. S. R.; OLIVEIRA NETO, W. O. A química orgânica acessibilizada por meio de kits de modelo molecular adaptados. Revista Educação Especial, Santa Maria, v. 28, n. 52, p. 473-86, maio/ago. 2015. Disponível em: <http://www.ufsm.br/revistaeducacaoespecial>. Acesso em: 20 out. 2018.
RESENDE FILHO, J. B. M. et al. Avaliação do nível de conhecimento dos alunos do ensino médio da cidade de João Pessoa com deficiência visual sobre as grafias Química e Matemática Braille. Revista Educação Especial, Santa Maria, v. 26, n. 46, p. 367-84, maio/ago. 2013. Disponível em: <http://www.ufsm.br/revista educacaoespecial>. Acesso em: 20 out. 2018.

SANTOS, S. N.; NORO, A. O uso de filmes como recurso pedagógico no ensino da neurofarmacologia. Interface: comunicação, saúde, educação, Botucatu, v. 17, n. 46, p. 705-14, jul./set. 2013. Disponível em: $<$ http://www.scielo.br/scielo.php?script= sci_abstract\&pid=S141432832013000300017\&lng=pt\&nrm =isō\&tlng=pt>. Acesso em: 20 out. 2018.

\section{SILVA FILHO, J. P. O ensino de Química para alunos} com baixa-visão - uma atitude positiva no processo de inclusão escolar. 2016. 49 p. Trabalho de Conclusão de Curso (Licenciatura em Química) - Instituto Federal de Rondônia, Campus Ji-Paraná, Ji-Paraná, 2016.

UNESCO. Declaração de Salamanca sobre princípios, política e práticas na área das necessidades educativas especiais. Salamanca, 1994.UNESCO, BR, 1998.

Disponível em:

$<$ http://unesdoc.unesco.org/images/0013/001393/139394por. Pdf $>$. Acesso em: 20 out. 2018.

VELTRONE, A. A.; MENDES, E. G. Diretrizes e Desafios na Formação Inicial e Continuada de Professores para a Inclusão Escolar. In: CONGRESSO ESTADUAL PAULISTA SOBRE FORMAÇÃO DE EDUCADORES, 9., 2007, Águas de Lindóia. Livro eletrônico. São Paulo: UNESP, 2011. Disponível em: <http://www.unesp.br/ prograd/ixcepfe/pagina012007.htm>. Acesso em: 20 out. 2018. 